\title{
A CLINICAL STUDY OF VAULT PROLAPSE IN TERTIARY CARE HOSPITAL
}

\author{
Chandrashekar $K^{1}$, Nataraj K. $C^{2}$
}

${ }_{1}^{1}$ Assistant Professor, Department of Obstetrics and Gynaecology, VIMS.

${ }^{2}$ Enumrites Professor, Department of Obstetrics and Gynaecology, JJMMC.

\section{ABSTRACT}

Objective of the study was to assess clinical parameters of patients with vault prolapse and its results of surgery. A prospective study of 11 patients with vault prolapse seen from October 2009 to July 2011 with 2 years of follow-up. Clinical parameter like age, parity, symptoms, POP-Q staging, type of previous hysterectomy and interval of onset of symptoms for prolapsed. All are presented with complaints of mass per vagina, next with difficulty in voiding urine. Majority of them are followed by vaginal hysterectomy then abdominal hysterectomy. 9 out of 11 were undergone sacrospinous ligament fixation and 2 are abdominal sacrocolpopexy done. The post-operative complications were fever in one patient and urinary tract infection in other patient. No recurrence of prolapsed noted up to 2 years of follow-up. Sacrospinous colpopexy is simple and efficacious procedure, which is indicated in vault prolapsed.

\section{KEYWORDS}

Vault Prolapsed, Sacrospinal Colpopexy.

HOW TO CITE THIS ARTICLE: Chandrashekar K, Nataraj KC. A clinical study of vault prolapse in tertiary care hospital. J. Evolution Med. Dent. Sci. 2016;5(7):330-332, DOI: 10.14260/jemds/2016/71

\section{INTRODUCTION}

From the turn of the century, a variety of surgical techniques has been described in an attempt to correct satisfactorily an eversion of the vagina after hysterectomy. Although it is not a common condition occurring only in about $1 \%$ of hysterectomies, Cruickshank. ${ }^{1}$ considers the incidence to be much higher. It is widely believed that vault prolapse is more common after vaginal hysterectomy than after abdominal hysterectomy. But Morely and DeLancey. ${ }^{2}$ state that vault prolapse results equally often after vaginal or abdominal hysterectomy. Until recently, no one technique that preserves sexual functions has been universally successful in the treatment of vaginal vault prolapse. Therefore many different approaches have been published. In the last several years, suspension of the prolapsed vaginal vault to the sacrospinous ligament has gained popularity in this country having previously been described in the European literature. ${ }^{3}$ Sacrospinous ligament fixation is most widely published procedures and has a good result with success rate exceeding 90\%.4 Special ligature carriers devised by Miya and by Deschcham are not indispensable and the operation can be perfectly done with a long needle holder as shown by Rajamaheswari and Gunasekharan. ${ }^{5}$ who describe the surgical steps in details.

Infracoccygeal sacropexy with a tension free tape has been reported on day care basis.6,7 It has a failure rate of $6 \%$. If a woman with vault prolapse needs laparotomy for any other reason, the vault can be suspended from either the hollow of the sacrum or the sacral promontory. It is possible to do sacrocolpopexy laparoscopically as shown by Cosson et al. ${ }^{8}$ But this takes much longer time, carries greater complication rate and needs further assessment.

Financial or Other, Competing Interest: None.

Submission 17-11-2015, Peer Review 05-01-2016,

Acceptance 16-01-2016, Published 22-01-2016.

Corresponding Author:

Dr. Chandrashekar $K$

M.V. Nagar, $2^{\text {nd }}$ Cross (Left),

Kappagal Road,

Ballari-583101.

E-mail: shekarinvims7@gmail.com

DOI: $10.14260 /$ jemds $/ 2016 / 71$
In our study made emphasize on the clinical features and management strategies with meticulous follow-up of the cases for 24 months.

\section{METHODS}

Cases for the present study were taken from Chigateri General Hospital, Women and Children Hospital and Bapuji Hospital from the period of October 2009 to July 2011. Total number of cases during the period were 11 . These patients were admitted to gynaec wards of the above hospital and were scheduled for Surgeries, i.e. sacrospinous ligament fixation or abdominal sacrocolpopexy. The following information were collected, i.e. patients age, detailed clinical history which included patient's complaints, duration and obstetric history any significant past, family and personal history, type of surgery that they undergone earlier, time interval between hysterectomy and development of vault prolapse and various treatment modalities that were tried. They were followed up after 6th weeks, 6th month, 1st years and 2nd year.

\section{RESULTS}

In our study, all patient with vault prolapse presented with a complaint of mass per vaginal $(100 \%)$, difficult in voiding of urine $(70 \%)$, dyspareunia and pain are seen in rest of cases revealed that $60 \%$ are in grand multipara group of which $40 \%$ are in para $4 ; 50 \%$ patients presented after 5 years of menopause which reflected increasing rate of prolapse are seen among patients with higher post hysterectomy.

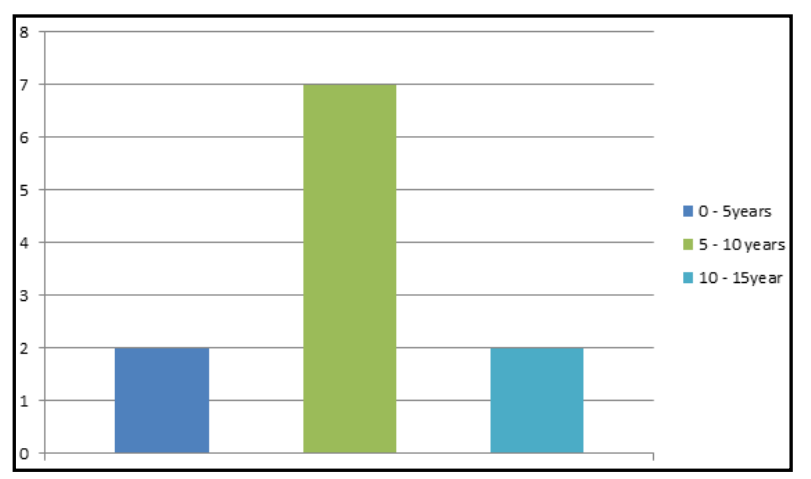

Chart 1: Duration in years from hysterectomy and manifestation of vault prolapse 
The mean interval between hysterectomy and seeking of treatment for vault prolapse was 8 (Table No. 1).

Out of 11 three are complete vault prolapse, i.e. cystocele, enterocele and rectocele are present and remaining eight are incomplete vault prolapse in which cystocele were 6 and 2 are both cystocele and enterocele.

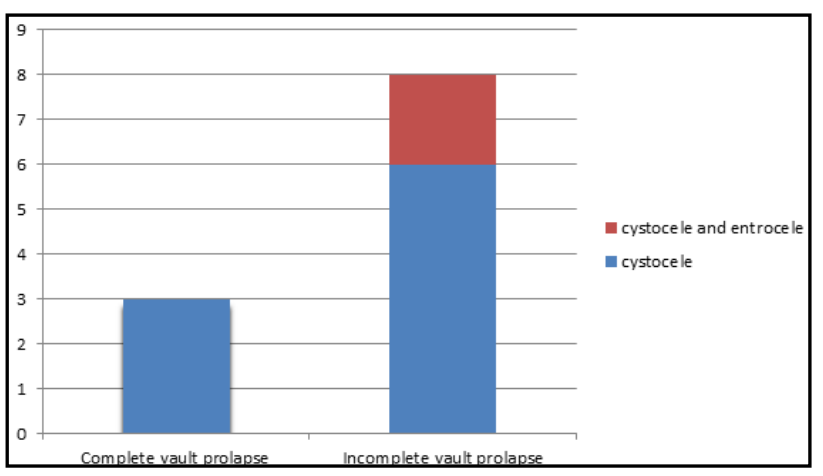

Chart 2: Incidence of complete and Incomplete vault prolapse

In all out of 11 cases, 7 had vaginal hysterectomy and 4 had abdominal hysterectomy.

In our study, we have seen incidence of vault prolapse with vaginal hysterectomy more (7 cases) than abdominal hysterectomy (4 cases), which are comparable to that of standard studies.

All 11 patients are underwent pelvic organ prolapse quantification, which resulted in majority are in stage III (70\%) POP-Q classification. For all patient who underwent vaginal hysterectomy with sacrospinous ligament fixation preoperatively POP Q done immediately after operation, again assessed by POPQ.

There is considerable change in the outcome. Almost vaginal length of $6 \mathrm{~cm}$ is retained after surgery.

\begin{tabular}{|lcc|}
\hline Pop Q points & Pre-op Pop Q in cm & Postop Pop Q in cm \\
\hline Aa & +1.5 & -2.5 \\
$\mathrm{Ba}$ & +4.5 & -4 \\
$\mathrm{Ap}$ & +1 & -2 \\
$\mathrm{Bp}$ & +3 & -3.8 \\
$\mathrm{D}$ & -1 & -6 \\
\hline \multicolumn{3}{|c|}{ Table 1: Comparison of POP-Q before } \\
and after the procedure \\
\hline
\end{tabular}

In our study, $87 \%$ underwent sacrospinous ligament fixation in patients with average duration for surgery of 1 hour 20 minutes for bilateral fixation, whereas for remaining 2 cases underwent abdominal sacrocolpopexy with Prolene mesh for average duration is 1 hour 40 minutes.

Out of 11 study group, 2 patients suffered febrile illness in which 1 patient was diagnosed to have urinary tract infection and 1 patient presented with complaint of buttock pain who underwent surgical procedure prolonged for more than 3 hours were treated with injection cobalamin for 5 days.

With a total of 2 years follow-up reflected that out of 11 patients 9 did not have any complaints which accounts to $90 \%$, one patient had first-degree cystocele and one patient had vault granuloma which is corrected with chemical cautery.

\section{DISCUSSION}

The relatively large number of women presenting to our hospital with advanced vault prolapse over a period of 24 months suggests it is a significant and perhaps underrated problem. When treating this condition the vaginal surgeon needs to appreciate the importance of recreating effective support at that time of vaginal hysterectomy.

When comparing complications with Cruikshank. ${ }^{1}$ and Dalal Malti. ${ }^{9}$ in our study fever was most common and did not come across for wound infection or stress urinary incontinence when compared to Cruikshank. But 3 patients had sciatica due to prolonged surgery, all 3 are recovered.

\begin{tabular}{|c|c|c|c|}
\hline Complications & $\begin{array}{c}\text { Cruikshank.1 } \\
\text { (1991) } \\
\text { (n=48) }\end{array}$ & $\begin{array}{c}\text { Malti et } \\
\text { al.9 } \\
(\mathbf{2 0 0 6 )} \\
(\mathbf{n = 3 5 )}\end{array}$ & $\begin{array}{c}\text { Present } \\
\text { Study }\end{array}$ \\
\hline Fever & 04 & 05 & 2 \\
\hline Buttock pain & - & - & 1 \\
\hline UTI & 03 & 04 & 1 \\
\hline Wound infection & - & 01 & - \\
\hline $\begin{array}{c}\text { Retention of } \\
\text { urine }\end{array}$ & - & 01 & - \\
\hline SUI & 02 & - & - \\
\hline Granuloma & - & - & - \\
\hline $\begin{array}{c}\text { Table 2: Comparison of complication in Cruikshank et } \\
\text { al. Malti et al. and present study }\end{array}$ \\
\hline
\end{tabular}

\section{CONCLUSION}

Sacrospinous ligament fixation is a definite treatment for vault prolapsed. This operative technique is successful in prevention of repeated vaginal vault prolapse. The vaginal route confirms an advantage by posing less anaesthetic risk and allowing simultaneous repair of other defects. If performed meticulously, complications are minimal. Operative time, blood loss and hospital stay are minimally increased.

\section{REFERENCES}

1. Cruickshank SH. Sacrospinous fixation-should this be performed at the time of vaginal hysterectomy? Am J Obstet Gynecol 1991;164:107-6.

2. Morley GN, DeLancey JO. Sacrospinous ligament fixation for eversion of vagina. Am J Obstet Gynecol 1988;158:8729.

3. Swift SE. The distribution of pelvic organ prolapse in routine gynaecologic health care. Am J Obstet Gynecol 2000;183:277-85.

4. Randall CL and Nichols DH (1971). Surgical treatment of vaginal inversion. Obstetrics and Gynaecology 38(3):327332.

5. Rajamaheshwari N, Karthik G (2004): Transvaginal sacrospinal colpopexy for vault prolapse. J Obstet Gynecol India 2004;54(3):275-7.

6. Ramalingappa Antartani, Kiran A (2007). Vault prolapse A clinical study. J Obstet Gynecol India Vol. 57, No. 3: Pg 245-247.

7. Farnswarth BN. Posterior intravaginal slingplasty (infracoccygeal sacropexy) for severe post-hysterectomy vaginal vault prolapse - a preliminary report on efficacy and safety. Int J Urogynecol Pelvic Floor Dysfunct 2002;13:4-8. 
8. Petros PE. Vault prolapse II: restoration of dynamic vaginal supports by infracoccygeal sacropexy, an axial day-care vaginal procedure. Int Urogynecol J Pelvic Floor Dysfunct 2001;12:296-303.
9. Dalal Malti, Verma Ragini N, Shah Tejal S, et al. (2006). Sacrospinous colpopexy for vault suspension during vaginal hysterectomy with repair for genital prolapse. The Journal of Obstetrics and Gynecology of India 56(3):247249. 